\title{
EDITORIAL
}

\section{Regional anesthesia for external cephalic version: its time has come}

\section{Journal of Perinatology (2010) 30, 569-570; doi:10.1038/jp.2010.89}

The rate of cesarean delivery reached an all time high of $31.8 \%$ in the United States in 2007. ${ }^{1}$ The total cesarean rate has risen by $50 \%$ in the past decade and shows no sign of slowing. Further, both components of the overall rate, primary and repeat cesareans are rising. As the vaginal birth after caesarean rate has fallen to its lowest level in more than 20 years, a woman with a primary cesarean delivery has a $>90 \%$ chance of repeat cesarean in subsequent pregnancies. These future pregnancies, then, are at increased risk for abnormal placentation with previa and accreta, ${ }^{2}$ other maternal morbidity ${ }^{3}$ and mortality, ${ }^{4}$ as well as stillbirth. ${ }^{5}$

Given these risks, preventing the first cesarean delivery should be a high priority for clinicians who care for pregnant women.

One common indication for a primary cesarean delivery is breech presentation, observed in $3 \%$ of pregnancies at term. ${ }^{6}$ Ever since the publication of the Term Breech Trial by Hannah et al., ${ }^{7}$ breech vaginal birth has decreased dramatically, ${ }^{8}$ with some estimates of $<5 \%$ of breech presentations delivered vaginally. ${ }^{6}$ Thus, breech presentation may lead to as many as 120000 cesareans per year. Not all of these are necessary, as there are techniques to encourage the fetus to convert to cephalic presentation: namely moxibustion and external cephalic version (ECV). Moxibustion is available from Chinese medicine providers. To a Western medicine provider, moxibustion sounds suspiciously like charlatanism, but in several prospective, randomized trials (one even published in JAMA) as well as in a meta-analysis, it has been shown to lead to a cephalic presentation more often than in women who did not receive moxibustion. ${ }^{9-11}$ To be clear, there are trials with negative findings, ${ }^{12}$ but the potential for effectiveness should clearly not be dismissed.

The primary option for a woman with a breech presenting fetus, however, remains ECV. This generally works $50-70 \%$ of the time, and is more successful in multiparas, in the setting of greater amniotic fluid volume, and earlier in gestation. ${ }^{13,14}$ Interestingly, it also may work better with regional anesthesia. ${ }^{15}$ Once the fetus is verted, it appears that the chances of achieving vaginal delivery are quite high, perhaps $>80 \%{ }^{16}$

In the current edition of the Journal of Perinatology, Yoshida et al. show the benefit of regional anesthesia in the setting of ECV in the form of a quality improvement effort conducted at their institution. ${ }^{17}$ The investigators made a decision in 2003 to offer regional anesthesia to all women undergoing ECV at their institution, but continued to offer ECV at 36-37 weeks gestation. They then examined women who underwent ECV before and after this policy change. The results are impressive: their ECV success rate went from 56 to $79 \%$ and their cesarean delivery rate in these women went from 50 to $33 \%$. Although these improved outcomes are superb, one must also acknowledge that this study was underpowered to examine some of the more rare outcomes associated with regional anesthesia such as hypotension leading to an immediate cesarean delivery, spinal headaches, and other complications. That being said, such outcomes would be much less common than the changes in more frequent outcomes that were improved.

A key difference in their protocol as compared with usual care was using the regional anesthesia at the 36- to 37-week trial of ECV. A strategy commonly observed in the United States is to do a trial of ECV at 36-37 weeks without regional anesthesia, and, if unsuccessful, to try again at 39 weeks under regional anesthesia before scheduled cesarean delivery. The thinking is that at 39 weeks if the ECV fails, the woman can have her cesarean at that time. This approach may fail to maximize the probability of success one gets from combining the earlier gestational age and regional anesthesia together.

Let's consider the potential benefits from the earlier use of regional anesthesia. If all 120000 women in the United States with a breech fetus were offered ECV with regional anesthesia, then approximately 90000 of them would vert to cephalic and perhaps only 40000 would undergo a cesarean delivery. Given the more traditional non-use of regional anesthesia, only approximately 66000 would vert, and 60000 would end up with a cesarean. Thus, this new practice could potentially prevent an additional 20000 primary cesareans each year. Given that $>90 \%$ of women with a previous vaginal delivery experience subsequent vaginal deliveries and that $>90 \%$ of women with a previous cesarean delivery experience subsequent cesarean deliveries, the downstream effects would be more like 38000 (20000 non-breech and 18000 repeats) prevented cesareans each year, only counting the subsequent pregnancy.

To be clear, any use of ECV would be appreciated, as we have observed the use of version declining in recent years. ${ }^{16}$ It is unclear why, but perhaps it is related to the hostile medicallegal environment, which is certainly associated with both decreased vaginal birth after caesarean and increased primary cesarean delivery rates. ${ }^{18}$ This is unfortunate as ECV has been 
shown to be a safe, cost-effective procedure that can lead to lower rates of cesarean delivery. ${ }^{19,20}$

So, for women with a breech presenting fetus, it is challenging to offer a breech vaginal delivery given the safety concerns as well as the dwindling number of providers with adequate experience in these potentially challenging deliveries. However, ECV should be offered to all appropriate candidates with a breech. And, if one is considering a version, it seems that the approach described by Yoshida et al. leads to the greatest success with accompanying regional anesthesia. Certainly, women at least deserve the option.

\section{Conflict of interest}

The authors declare no conflict of interest.

\section{AB Caughey ${ }^{1,2}$ and YY El-Sayed ${ }^{2}$ \\ ${ }^{1}$ Department of Obstetrics, Gynecology and Reproductive} Sciences, University of California, San Francisco, CA, USA and ${ }^{2}$ Department of Obstetrics and Gynecology, Stanford University Medical Center, Stanford, CA, USA E-mail:abcmd@berkeley.edu

\section{References}

1 Hamilton BE, Martin JA, Ventura SJ. Births: preliminary data for 2007. Natl Vital Stat Rep 2009; 57: 1-23.

2 Silver RM, Landon MB, Rouse DJ, Leveno KJ, Spong CY, Thom EA et al. Maternal morbidity associated with multiple repeat cesarean deliveries. Obstet Gynecol 2006; 107: $1226-1232$.

3 Galyean AM, Lagrew DC, Bush MC, Kurtzman JT. Previous cesarean section and the risk of postpartum maternal complications and adverse neonatal outcomes in future pregnancies. J Perinatol 2009; 29: 726-730.

4 Clark SL, Belfort MA, Dildy GA, Herbst MA, Meyers JA, Hankins GD. Maternal death in the 21st century: causes, prevention, and relationship to cesarean delivery. Am J Obstet Gynecol 2008; 199(1): 36e1-36.e5; discussion 91-2. e7-11.
5 Smith GC, Pell JP, Dobbie R. Caesarean section and risk of unexplained stillbirth in subsequent pregnancy. Lancet 2003; 362(9398): 1779-1784.

6 Gilbert WM, Hicks SM, Boe NM, Danielsen B. Vaginal versus cesarean delivery for breech presentation in California: a population-based study. Obstet Gynecol 2003; 102: $911-917$.

7 Hannah ME, Hannah WJ, Hewson SA, Hodnett ED, Saigal S, Willan AR et al. Planned caesarean section versus planned vaginal birth for breech presentation at term: a randomised multicentre trial. Lancet 2000; 356: 1375-1383.

8 Rietberg C, Elfernik-Stinkens P, Visser G. The effect of the Term Breech Trial on medical intervention behaviour and neonatal outcome in The Netherlands: an analysis of 35453 term breech infants. BJOG 2005; 112: 205-209.

9 Cardini F, Weixin H. Moxibustion for correction of breech presentation: a randomized controlled trial. JAMA 1998; 280: 1580-1584.

10 Neri I, Airola G, Contu G, Allais G, Facchinetti F, Benedetto C. Acupuncture plus moxibustion to resolve breech presentation: a randomized controlled study. J Matern Fetal Neonatal Med 2004; 15: 247-252.

11 Coyle ME, Smith CA, Peat B. Cephalic version by moxibustion for breech presentation. Cochrane Database Syst Rev 2005; (2). Art. no.: CD003928.

12 Guittier MJ, Pichon M, Dong H, Irion 0, Boulvain M. Moxibustion for breech version: a randomized controlled trial. Obstet Gynecol 2009; 114(5): 1034-1040.

13 Kok M, Cnossen J, Gravendeel L, Van Der Post JA, Mol BW. Ultrasound factors to predict the outcome of external cephalic version: a meta-analysis. Ultrasound Obstet Gynecol 2009; 33(1): 76-84.

14 Hutton EK, Hofmeyr GJ. External cephalic version for breech presentation before term. Cochrane Database Syst Rev 2006; (1). Art. no.: CD000084

15 Mancuso KM, Yancey MK, Murphy JA, Markenson GR. Epidural analgesia for cephalic version: a randomized trial. Obstet Gynecol 2000; 95: 648-651.

16 Clock C, Kurtzman J, White J, Chung JH. Cesarean risk after successful external cephalic version: a matched, retrospective analysis. J Perinatol 2009; 29(2): 96.

17 Yoshida M, Matsuda H, Kawakami Y, Hasegawa Y, Yoshinaga Y, Hayata E et al. Effectiveness of epidural anesthesia for external cephalic version (ECV). J Perinatol 2010; 30(9): 580-583.

18 Yang YT, Mello MM, Subramanian SV, Studdert DM. Relationship between malpractice litigation pressure and rates of cesarean section and vaginal birth after cesarean section. Med Care 2009; 47(2): 234-242.

19 Grootscholten K, Kok M, Oei SG, Mol BWJ, van der Post JA. External cephalic versionrelated risks a meta-analysis. Obstet Gynecol 2008; 112: 1143-1151.

20 Tan JM, Macario A, Carvalho B, Druzin ML, El-Sayed YY. Cost-effectiveness of external cephalic version for term breech presentation. BMC Pregnancy Childbirth 2010; 10: 3. 